\title{
Gra w ludowe. Czy kultura ludowa dziś inspiruje? Uwagi wstępne
}

\section{The Folk Game: Does the Folk Culture Still Inspire Today? Preliminary Comments}

Nie ma już wsi znanej z powstałych ponad sto lat temu Chłopów czy wydanej niemal przed półwieczem Konopielki. Czy jednak kultura ludowa i świat wsi przestały być inspiracją dla polskiej literatury? Gdy Andrzej Zawada - od którego zapożyczamy tytuł tego zeszytu - wydawał w 1983 roku swoją książkę, stawiał pytanie, „w jakim stopniu tradycyjna kultura wsi może tę [ówcześnie powstająca - dop. D.S.] kulturę wzbogacić, a na ile w tym procesie przemieszczania i zrastania się kultur zostanie ona obrana z wartości, które zaginą bezpowrotnie"1. Po upływie czterdziestu lat możemy zarówno obserwować przekształcenia nurtu chłopskiego w literaturze, ponawiać - może w innym nieco brzmieniu - tamto pytanie, stawiając je naszej współczesności, ale i postrzegać chłopskość oraz ludowość w nowych perspektywach. I tak na przykład opozycja kultura wsi-kultura miasta uległa zatarciu, kwestia awansu społecznego nie budzi takich emocji jak w czasach kształtowania się prozy nurtu chłopskiego, a problem wyobcowania wpisywany jest w inne konteksty. Natomiast bardziej interesujące wydaje się na przykład pytanie o dziedzictwo chłopskości w polskiej mentalności i tożsamości. Kłopotem nadal pozostają odnotowywane przez Zawadę trudności z definiowaniem chłopskości/ludowości/ wiejskości, choć toczono już od tego czasu wiele dyskusji i sporów. Znajduje to odzwierciedlenie także w tytule naszego zeszytu, brakuje bowiem terminu, który - nie budząc wątpliwości - obejmowałby całe spektrum zjawisk związanych z wsią, jej historią i kulturą.

Nie ulega wątpliwości, że dawną kulturę ludową zastąpiły inne formy. Częściowo została ujednolicona, upodobniła się do kultury miejskiej, przemianom

${ }^{1}$ A. Zawada, Gra w ludowe. Nurt chtopski w prozie wspótczesnej a kultura ludowa, Warszawa 1983, s. 6. 
podlegały jej istotne wyróżniki. Zagadnienia te należą do socjologii, antropologii kultury, etnografii, dla literaturoznawców istotne jest jednak, czy tematy związane z realiami wiejskimi, chłopską historią i ludową kulturą są podejmowane przez pisarzy i oczywiście w jaki sposób. Zwłaszcza że stosunek do ludu i jego kultury w polskiej tradycji był nie tylko kwestią istotną, ale i ambiwalentna, co podkreślała już 1975 roku Maria Janion². Na przełomie lat siedemdziesiątych i osiemdziesiątych, gdy nurt chłopski przeżył swoje apogeum, zainteresowanie relacjami między wiejskim a miejskim znalazło odzwierciedlenie w badawczych syntezach. Zagadnienia te podejmował na przykład Roch Sulima w książkach Folklor i literatura ${ }^{3}$ czy Literatura a dialog kultur ${ }^{4}$. W ostatnich latach ponownie temat chłopski - używając bardzo szerokiego i nieprecyzyjnego określenia - staje się przedmiotem rozważań i analiz. Na plan pierwszy wysuwają się kwestie historyczne rozpatrywane w kontekście socjologiczno-tożsamościowym (Fantomowe ciato króla Jana Sowy') oraz przemiany polityczno-ekonomiczne i ich odbicie w literaturze, społecznej świadomości (Prześniona rewolucja Andrzeja Ledera $\left.{ }^{6}\right)$. Ostatnio pojawiła się kolejna, ważna dla tematu pozycja, od razu wywołująca głosy polemiczne, Ludowa historia Polski Adama Leszczyńskiego7. Wieś powraca też w refleksji stricte literaturoznawczej. Dowodem między innymi interesujący numer monograficzny „Tekstów Drugich" zatytułowany Chtopskośs ${ }^{8}$. Grzegorz Grochowski we wprowadzeniu odnotowuje wzrost zainteresowania tematem wsi nie tylko w literaturze, ale i szerzej w kulturze i humanistyce, a także towarzyszące tym powrotom kontrowersje. Wskazuje punkty wspólne tych współczesnych nawiązań: znaczenie chłopskiego pochodzenia w kształtowaniu polskiej mentalności oraz kwestię poddaństwa ${ }^{9}$ (czy może relacji chłopskość-szlacheckość). Ważnym tekstem poruszającym interesującą nas tu tematykę jest artykuł Przemysława Czaplińskiego, w którym autor omawia przemiany usytuowania wsi w literaturze polskiej przełomu XX i XXI wieku ${ }^{10}$. Zagadnieniom tym poświęcona została inna istotna publikacja - tom zbiorowy Chtopska (nie)pamięć. Dziedzictwo chtopskości w polskiej literaturze i kulturze pod redakcją Grzegorza Grochowskiego, Doroty Krawczyńskiej i Grzegorza Wołowca ${ }^{11}$ (znalazły się w nim niektóre artykuły

2 M. Janion, Ludowość rozdwojona, „Literatura” 1975, nr 2. Przedruk: taż, Odnawianie znaczeń, Kraków 1980.

3 R. Sulima, Folklor i literatura, Warszawa 1976.

${ }^{4}$ Tenże, Literatura a dialog kultur, Warszawa 1982.

5 J. Sowa, Fantomowe ciato króla, Kraków 2011.

${ }^{6}$ A. Leder, Prześniona rewolucja, Warszawa 2014.

7 A. Leszczyński, Ludowa historia Polski, Warszawa 2020.

${ }^{8}$ Chtopskość, „Teksty Drugie” 2017, nr 6.

9 G. Grochowski, Kwestia chtopska, „Teksty Drugie” 2017, nr 6, s. 7-12.

${ }_{10}$ P. Czapliński, Śmierć, śmierć, inne życie. Wieśs literaturze polskiej przetomu XX i XXI wieku, „Teksty Drugie” 2017, nr 6, s. 13-35.

${ }_{11}$ Chtopska (nie)pamięć. Dziedzictwo chtopskości w polskiej literaturze i kulturze, red. G. Grochowski, D. Krawczyńska, G. Wołowiec, Kraków 2019. 
z „Tekstów Drugich”). Szczegółowe omówienie tej monografii autorstwa Małgorzaty Tarnowskiej zamieszczamy w tym zeszycie.

Zaczynamy jednak od innego ujęcia tematu. Muzyka, sztuka, opowieści i ludowa wyobraźnia pobudzały twórcze działania. Czy mogą i dziś tak oddziaływać? Refleksję o inspiracjach kulturą ludową podejmuje Andrzej Bieńkowski, który od ponad czterdziestu lat prowadzi badania etnograficzne w ramach projektu Muzyka Odnaleziona. Obserwując przemiany zachodzące w odbiorze muzyki wiejskiej, rozważa szanse na jej twórcze wykorzystanie. Jako malarz poświęca też uwagę zarówno twórcom czerpiącym ze źródeł tradycji ludowej, jak i artystom wiejskim.

Artykuły głównego bloku tematycznego koncentrują się jednak wokół zagadnień poruszanych w wymienionych wcześniej publikacjach. Dobrosława Wężowicz-Ziółkowska pisze o kulturze ludowej, która stała się kulturą bez podmiotu, stąd rozpatrywanie jej w kontekście zagadnień związanych z wiedzą o pamięci i przeszłości. Analizując procesy zachodzących przemian przez pryzmat opozycji restytucja-zawłaszczenie, polemizuje też autorka z postrzeganiem kultury ludowej jako współczesnej kultury popularnej.

Pamięć istotna jest również dla Karoliny Koprowskiej, choć w zawężeniu do tematyki związanej z Holokaustem i okresem okupacji. W artykule Spóźniona odpowiedź? Literackie kontrnarracje o wsi i Zagtadzie stawia pytanie o przyczyny podejmowania w literaturze najnowszej wątku wsi uwikłanej w Zagładę. Swoje rozważania odnosi do badań historycznych dotyczących tak zwanej trzeciej fali Holokaustu. Za reprezentatywne uznaje tu książki Sońka Ignacego Karpowicza i Mała Zagtada Anny Janko. Kontrowersje wokół narracji o Zagładzie i udziale w niej polskiego chłopstwa czynią analizę literackich ująć tematu szczególnie istotną.

Natomiast Marta Tomczok w szkicu Narzędzia powrotu. Ludowe, wiejskie i chtopskie w poezji Piotra Szewca omawia twórczość poety poza aktualną dyskusją o miejscu wsi w polskiej kulturze. Autorka sytuuje motywy wierszy związane z wiejskimi realiami (zwłaszcza nazwy narzędzi) w kontekście filozofii rzeczy i kabały żydowskiej. Formułuje też tezę o destrukcji mitycznego wzorca, do którego odnoszony był obraz wsi w polskiej literaturze drugiej połowy XX wieku.

Dariusz Nowacki poświęca swój tekst (Obecność Szeli. Trzy przyktady z nowej prozy) analizie wątku rebelii chłopskiej z 1946 roku i postaci Jakuba Szeli w nagrodzonej Nike powieści Radka Raka oraz w utworach Macieja Hena i Stanisława Aleksandra Nowaka. Autor, odnosząc się do tezy Przemysława Czaplińskiego o znaczeniu rabacji dla dzisiejszych protestów przeciwko różnym formom wyzysku, rozważa miejsce mitu Szeli w najnowszej prozie i w popkulturze. Polemika prowadzi do konstatacji o braku w omawianych powieściach głębszej refleksji o chłopskim dziedzictwie w kontekście postaw społecznego buntu, a tym samym o rozbieżności między postulatami historyków i socjologów a twórczością literacką. 
Poza blokiem tematycznym publikujemy dwa inne artykuły: analizę Wojciecha Wróblewskiego Dwie antyutopijne wizje - „My” Jewgienija Zamiatina $i$ "Miranda” Antoniego Langego. Z dziejów idei i recepcji oraz rozważania Kariny Jarzyńskiej Po co czytać Harolda Blooma i jak, czyli o kanoniczności krytyka. Autorka prezentuje syntezę poglądów Harolda Blooma na literaturę i kulturę Zachodu oraz analizuje jego twórczość krytyczną, rozważając zarówno jej oryginalność, jak i ograniczenia.

Zeszyt zamyka recenzja Agnieszki Romanowskiej interesującej książki Jean Ward The Between-Space of Translation: Literary Sketches, wydanej w 2020 roku, która wykorzystując własne doświadczenie, pisze o zagadnieniach przekładu literackiego, między innymi w kontekście spotkania kultur.

Dorota Siwor Redaktor prowadzaca zeszytu 